\section{Prolonged Drought and Recovery Responses of Kentucky Bluegrass and Ornamental Groundcovers}

\author{
Jacob C. Domenghini \\ Department of Agricultural and Industrial Technologies, IL Central College, \\ East Peoria, IL 61635
}

\author{
Dale J. Bremer ${ }^{1}$, Jack D. Fry, and Gregory L. Davis \\ Department of Horticulture, Forestry, and Recreation Resources, Kansas \\ State University, Manhattan, KS 66506
}

Additional index words. drought resistance, drought resistant, nursery and landscape plants, severe drought, water restrictions

\begin{abstract}
Municipalities often restrict irrigation of urban landscapes, causing plants to experience drought stress. Few data are available regarding drought resistance of nonturfgrass landscape species. This study evaluated the performance of one turfgrass (Poa pratensis L. 'Apollo') and eight herbaceous landscape species (Achillea millifolium L., Ajuga reptans L. 'Bronze Beauty', Liriope muscari Decne., Pachysandra terminalis Siebold and Zucc., Sedum album L., Thymus serpyllum L., Vinca major L., and Vinca minor L.) during a severe drydown and subsequent recovery. This greenhouse study was conducted in the spring/summer and again in the fall of 2010. S. album performed the best, averaging 254 days to decline to a drought rating of 1 (1 to 9 scale, $1=$ dead/dormant and $9=$ best quality). $L$. muscari and $P$. terminalis also performed well, averaging 86 days to a drought rating of 1. $V$. minor and $V$. major declined faster than the previous species, averaging 63 days. A. millifolium, $A$. reptans, $P$. pratensis, and $T$. serpyllum declined the fastest to a drought rating of 1 (mean 52 days). Thereafter, the only species to recover after 60 days of resuming irrigation were $P$. pratensis $[46 \%$ pot cover (PC)], S. album (38\% PC), and $V$. major (35\% PC) in the spring/summer study; no species recovered during the fall study. Results indicate $S$. album, $L$. muscari, and $P$. terminalis are the most drought-resistant among the species evaluated in landscapes where severe drought may occur. $V$. minor and $V$. major are good selections in less severe droughts as is $\boldsymbol{P}$. pratensis if periods of dormancy are acceptable.
\end{abstract}

Water resources continue to be depleted as the world's population grows. American families can use up to $1500 \mathrm{~L}$ of water per day, and more than $50 \%$ may be used outdoors (Smith and Brown, 2003). Alig et al. (2004) used population and land development models to predict urbanization to increase by as much as $80 \%$ between 2004 and 2025, indicating more land will be used for irrigated residential and commercial landscapes. This, along with already limited water supplies, illustrates a need for conserving water in the lawn and landscape. Selection of drought-tolerant species for use in the landscape may be one solution.

It is not uncommon for water municipalities to impart water restrictions on residential landscapes, which can cause plants to experience drought stress. Including plants in the landscape that have the ability to maintain their quality longer or experience dormancy during drought, and recover afterward, would

\footnotetext{
Received for publication 25 Mar. 2013. Accepted for publication 8 July 2013 .

This research was funded by the USDA National Integrated Water Quality Program and the Kansas Turfgrass Foundation.

${ }^{1}$ To whom reprint requests should be addressed; e-mailbremer@ksu.edu.
}

be beneficial in areas with water restrictions and contribute to reduced water use in areas without water restrictions. A number of studies have evaluated drought tolerance of turfgrass species in the greenhouse or growth chamber (Huang and Gao, 1999; Jiang and Huang, 2001; Liu et al., 2007; Qian and Fry, 1997) or in the field (Hook et al., 1992; Karcher et al., 2008; Merewitz et al., 2010; Richardson et al., 2008; Steinke et al., 2010). Few studies, however, have assessed drought resistance of ornamental landscape species or directly compared drought resistance between turf and non-turf groundcovers (Devitt and Morris, 2008; Domenghini et al., 2013; Staats and Klett, 1995).

Previous research has indicated succulents such as those in the Sedum genus have performed well on green roofs, where moisture is typically a limiting factor (Bousselot et al., 2010, 2011; Kircher, 2004; Monterusso et al., 2005). One reason Sedum is well suited for possible drought situations such as on green roofs is that it has the ability to switch from using a $\mathrm{C}_{3}$ photosynthetic pathway to a crassulacean acid metabolism photosynthetic pathway when growing in an environment where water is limiting (Phillips and Burrell, 1993; Sayed et al., 1994). This minimizes water loss during the day, when temperatures and evaporation are highest.
Among cool-season grasses, Poa pratensis is the most commonly used in the United States for residential and commercial lawns, parks, and golf courses (Christians, 2004; Lyman et al., 2007; Turgeon, 2005). One advantage of $P$. pratensis is its ability to survive during extended drought through dormancy (Christians, 2004; Goldsby, 2013). Drought resistance of $P$. pratensis has been studied by initiating severe drydowns and evaluating plant responses (Keeley and Koski, 2001; Liu et al., 2007; Merewitz et al., 2010; Richardson et al., 2008, 2009). Richardson et al. (2009) found wide variation in responses to drought among $P$. pratensis cultivars and suggested selection of better-performing cultivars could result in water conservation.

Turfgrasses are often singled out for replacement by presumably more water-efficient plant species to save water. For example, in 2006, the U.S. Environmental Protection Agency (EPA) created a voluntary program called WaterSense to promote water efficiency (WaterSense, 2008). This program lists criteria for builders to follow to have a home labeled a WaterSense home. At the inception of WaterSense in 2006, the outdoor water efficiency component of the program required a reduction in the area of turfgrass in the landscape for the home to qualify for the WaterSense label. Research is needed, however, to either validate or refute claims that turfgrass uses more water or is less droughtresistant than herbaceous ornamentals.

The objectives of this study were to: 1) evaluate visual drought stress and water status of one turfgrass and eight herbaceous non-turf ornamental landscape species during a severe drydown; and 2) evaluate percentage of green groundcover of the same species during recovery from the severe drydown.

\section{Materials and Methods}

Preparation and maintenance of plants in nursery containers. Two studies were conducted to evaluate performance among species during severe drydowns. One study was conducted in the spring/summer and a second in the fall of 2010. Large nursery containers ( $25 \mathrm{~cm}$ diameter $\times 29.5 \mathrm{~cm}$ deep) were used to minimize root restrictions among species. The containers were filled with field soil from the Rocky Ford Turfgrass Research Center near Manhattan, KS. The soil was a Chase silt loam (fine, smectitic, mesic, Aquertic, Argiudolls). The bulk density inside the nursery containers was $1.53 \mathrm{~g} \cdot \mathrm{cm}^{-3}$. Plant species were established in the Throckmorton Plant Sciences Center greenhouse complex in Manhattan, KS (lat. 39 $11^{\prime} 40^{\prime \prime} \mathrm{N}$, long. 96³5' 5" W). One turfgrass species, $P$. pratensis 'Apollo', a compact type known for good drought tolerance (Christians, 2004; Goldsby, 2013; Turgeon, 2005), and eight commonly used ornamental landscape species were selected for the study. The ornamental species were Achillea millifolium, Ajuga reptans 'Bronze Beauty', Liriope muscari, Pachysandra terminalis, Sedum album, Thymus serpyllum, Vinca major, and Vinca minor. Turfgrass was established in 
nursery containers with sod from the Rocky Ford Turfgrass Research Center. The ornamental species were established by washing the substrate from the roots of three plants grown in nursery containers $(11.4 \mathrm{~cm}$ diameter $\times 9.5 \mathrm{~cm}$ deep), purchased from a local garden center, and transplanted to the $25-\mathrm{cm}$ diameter containers. Three nursery containers of each species were established in each study as replicates.

Continuous measurements of air temperature, relative humidity, and photosynthetically active radiation $(P A R)$ were recorded at canopy height in the same vicinity as the containers during establishment and throughout each study. Air temperature and relative humidity were measured using a shaded, ventilated sensor (CS500; Campbell Scientific, Logan, UT) and $P A R$ was measured using a quantum sensor (LI-190SA; LI-COR, Lincoln, $\mathrm{NE}$ ). Measurements were automatically logged every minute and then averaged and recorded every hour with a micrologger (CR10; Campbell Scientific).

Establishment of plants for the spring/ summer study took place in the greenhouse from 19 Nov. 2009 through 17 May 2010. Average day/night air temperature was 25/ $23^{\circ} \mathrm{C}$ and supplemental light was included for $12 \mathrm{~h} \cdot \mathrm{d}^{-1}$. Plants for the fall study were also established in the greenhouse from 6 June 2010 through 26 Sept. 2010. Average day/ night air temperature was $26 / 26{ }^{\circ} \mathrm{C}$ and no supplemental light was used because establishment was during the summer. Daily maximum PAR during establishment of the plants ranged from 296 to $874 \mu \mathrm{mol} \cdot \mathrm{m}^{-2} \cdot \mathrm{s}^{-1}$ (spring/ summer) and 362 to $1207 \mu \mathrm{mol} \cdot \mathrm{m}^{-2} \cdot \mathrm{s}^{-1}$ (fall). Containers were maintained well watered during establishment of both studies and fertilized $\approx 60 \mathrm{~d}$ before the beginning of the drydown at a rate of $49 \mathrm{~kg}$ nitrogen/ha $(46 \mathrm{~N}-0 \mathrm{P}-0 \mathrm{~K})$. Turfgrass in the containers was mowed once weekly at $9 \mathrm{~cm}$ and both turfgrass and ornamentals were kept trimmed to the outside edge of the container to keep the area of vegetation cover consistent among species. Establishment periods lasted until full pot cover was reached and the drydowns did not begin until the establishment period ended. Full pot cover was reached sooner during the establishment of the fall study because establishment was during the summer.

Insecticide applications for controlling aphids, white fly, spider mites, and scale during the establishment period included imidacloprid \{1-[(6-chloro-3-pyridinyl)methyl]$\mathrm{N}$-nitro-2-imidazolidinimine $\}$ at $0.014 \mathrm{~kg}$ a.i./ha on 12 Jan. 2010 and 2 Feb. 2010; spinosad [mixture of (spinosyn $\mathrm{A}, \mathrm{R}=\mathrm{H}$ ) and (spinosyn $\mathrm{D}, \mathrm{R}=\mathrm{CH}_{3}$ )] at $0.2 \mathrm{~kg}$ a.i./ha on 12 Jan. 2010; bifenazate \{hydrazine carboxylic acid, 2-[4-methoxy-(1,1-biphenyl)-3-yl] 1 -methylethyl ester $\}$ at $0.06 \mathrm{~kg}$ a.i./ha on 2 Feb. 2010 and 10 Sept. 2010; buprofezin (2tert-butylimino-3-isopropyl-5-phenylperhydro1,3,5-thiadiazin-4-one) at $0.4 \mathrm{~kg}$ a.i./ha on 9 Mar. 2010; and pymetrozine [6-methyl-4(pyridine-3-ylmethylideneamino)-2,5-dihydro1,2,4-triazin-3-one] at $0.37 \mathrm{~kg}$ a.i./ha on 10 Sept. 2010.
Once plants were established, containers were arranged in the greenhouse in a randomized complete block design with three replications. To begin the severe drought, irrigation of the containers ceased on 18 May 2010 for the spring/summer study and 27 Sept. 2010 for the fall study. No irrigation was applied during each drydown. Drought effects ratings, container weight, soil moisture, and a number of physiological factors described below were measured until the plants were either dormant or dead. Irrigation was then applied to the container and percentage of green groundcover was evaluated for $60 \mathrm{~d}$ to determine the level of recovery, if any, from the severe drought.

Supplemental light was not used during the spring/summer study but was used in the fall study for $16 \mathrm{~h} \cdot \mathrm{d}^{-1}$ to simulate the longer daylengths during the spring/summer study. Daily maximum $P A R$ during each study ranged from 267 to $909 \mu \mathrm{mol} \cdot \mathrm{m}^{-2} \cdot \mathrm{s}^{-1}$ (spring/summer) and 301 to $1180 \mu \mathrm{mol} \cdot \mathrm{m}^{-2} \cdot \mathrm{s}^{-1}$ (fall).

Container water loss, soil moisture, drought ratings, and stomatal conductance. Measurements of container water loss, volumetric soil water content $\left(\theta_{\mathrm{v}}\right)$, and drought ratings were taken three times per week. Container water loss was measured by weighing containers to the nearest gram using an electronic balance (Model GMBH; Sartorius, Gottingen, Germany). Measurements of $\theta_{\mathrm{v}}$ in the 0 - to $20-\mathrm{cm}$ soil profile were taken using a time domain reflectometer (Model 6050X1; Soilmoisture Equipment Corp., Santa Barbara, CA). Measurements of container water loss and $\theta_{\mathrm{v}}$ were taken until the plant in the container had declined to a drought rating of 1 .

\section{Achillea millifolium $\square \triangle$ Pachysandra terminalis $\square$ Thymus serpyllum

$\begin{array}{lll}\square \text { Ajuga reptans } & \square \text { Poa pratensis } & \square \text { Vinca major } \\ \square \text { Liriope muscari } & \square \text { Sedum album }\end{array}$
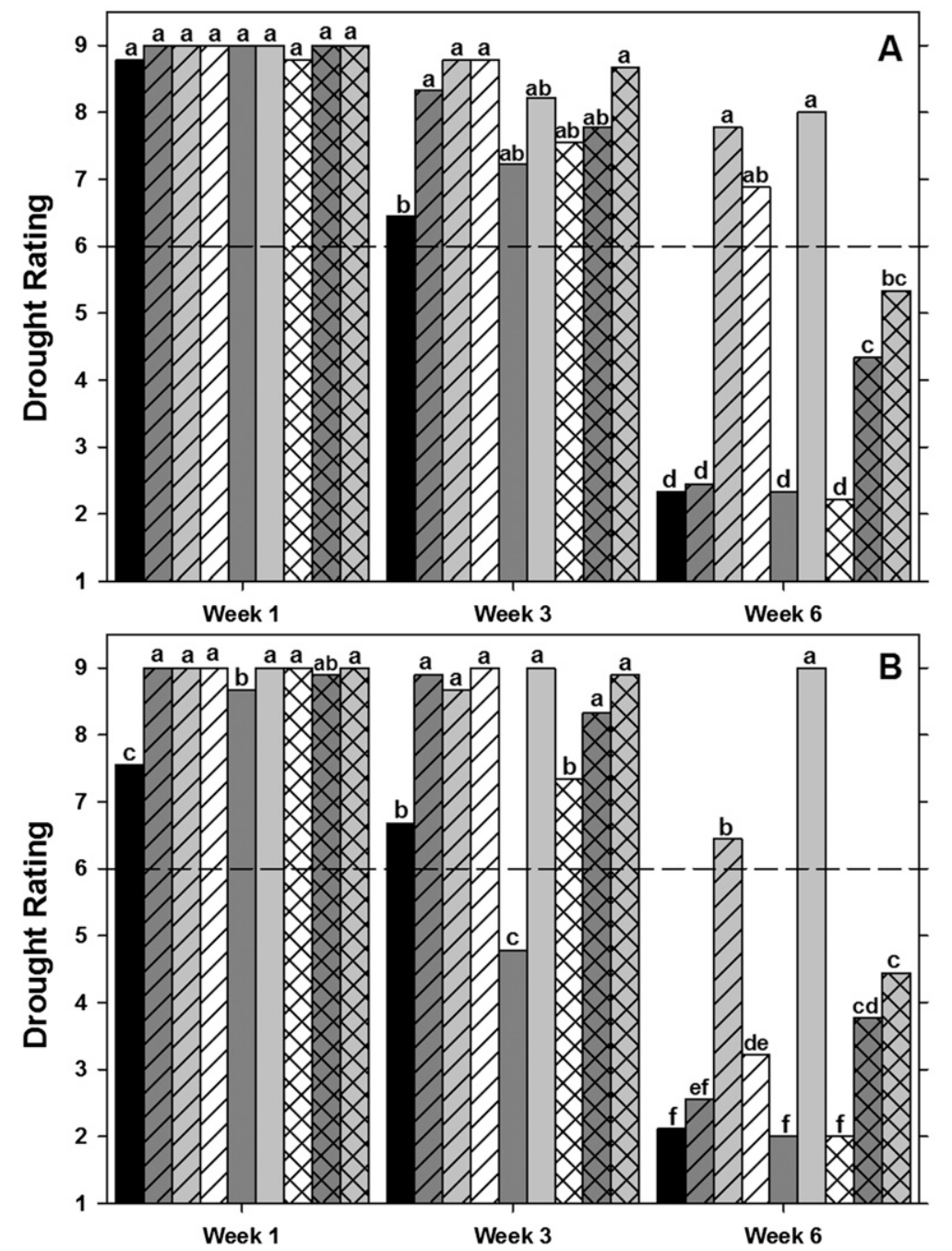

Fig. 1. Visual estimates of plant drought ratings of each species for Weeks 1, 3, and 6 of the spring/summer [(A) (began 18 May 2010)] and the fall [(B) (began 27 Sept. 2010)] drydown. Termination dates of each study varied with species (see text for details). Horizontal dashed line indicates minimal acceptability (drought rating of 6). Means followed by the same letter within each week are not significantly different $(P=0.05)$. 
Drought ratings were evaluated visually using a scale of 1 to $9(1=$ brown/dead, $6=$ minimally acceptable for home landscape, and 9 = optimum quality). This scale is the standard for evaluating turfgrass in the National Turfgrass Evaluation Program (NTEP; Morris, 2000). To maintain as much consistency as possible in drought ratings among ornamental and turfgrass species, the standard scale used for evaluating drought by NTEP was adapted to ornamentals. The amount of wilt or leaf firing affected the drought rating with greater wilt or leaf firing resulting in a lower drought rating. Percentage of green groundcover was evaluated during the recovery phases of both studies using a similar scale of 1 to $9(1=$ no green cover, $6=\approx 50 \%$ green cover, $9=100 \%$ green cover).

Stomatal conductance $\left(g_{\mathrm{S}}\right)$ was measured at the beginning stages of the drydown 2 to $8 \mathrm{~d}$ to eight days, when sky conditions were clear, using a steady-state diffusion porometer (SC-1; Decagon Devices, Pullman, WA). One living leaf of the ornamentals was randomly selected near the top of the canopy and five or six $P$. pratensis leaves growing close to one another (enough to cover the measurement chamber orifice) were selected for measurements. One measurement was taken per container. Stomatal conductance was no longer detectable in any species after 35 and $36 \mathrm{~d}$ of treatment (DOT) during the spring/summer and fall studies, respectively.

To evaluate possible effects of $P A R$ on $g_{\mathrm{S}}$, $P A R$ was measured with a quantum sensor (LI-190SA; LI-COR) between each $g_{\mathrm{S}}$ measurement. All measurements of $g_{\mathrm{S}}$ and $P A R$ generally required $\approx 30 \mathrm{~min}$ on each measurement day. Stomatal conductance was not measured on three species (A. millifolium, T. serpyllum, and $S$. album) because their leaves were too small to cover the measurement chamber orifice of the porometer.

Data analysis. Weekly averages of total water loss, drought ratings, and $\theta_{\mathrm{v}}$ data were calculated among species. Water loss, drought ratings, and $\theta_{\mathrm{v}}$ were analyzed for differences among species using the general linear model procedure in SAS as a randomized complete block design (SAS Institute, Cary, NC). Means were separated using Fisher's protected least significant difference (LSD) at $P=0.05$.

Stomatal conductance data were evaluated for differences among species on each measurement day. As a result of missing data points in $g_{\mathrm{S}}$, the mixed model procedure in SAS was used. Means were separated using LSD at $P=0.05$. Stomatal conductance was below detectable limits in some containers within a species treatment near the end of each drydown, resulting in no recorded measurement.

\section{Results and Discussion}

There was a significant interaction between the two studies; therefore, data from each study are presented separately.

Drought ratings. To illustrate transient trends among species, average drought ratings are presented for Weeks 1, 3, and 6 (Fig. 1).
During the spring/summer study, individual containers of some species had declined to a drought rating of 1 by Week 6 (i.e., no data were collected from those containers thereafter). On average, all species maintained minimal acceptable drought ratings (6 or higher) through Week 3 in both studies with the exception of $P$. pratensis in the fall. In a field study conducted in the summer in New Jersey, visual turf quality in two $P$. pratensis cultivars also dropped below a rating of 6 by 2 to
3 weeks after irrigation was curtailed (Merewitz et al., 2010). In a field study conducted in the summer near the present greenhouse study, the visual quality of $P$. pratensis declined below 6 by $\approx 2$ weeks after beginning a water-deficit treatment of $20 \%$ of evapotranspiration replacement (Fu et al., 2004).

S. album and L. muscari maintained drought ratings higher than 6 through Week 6 of both drydowns (Fig. 1), longer than all other species. The drought ratings of $P$. terminalis

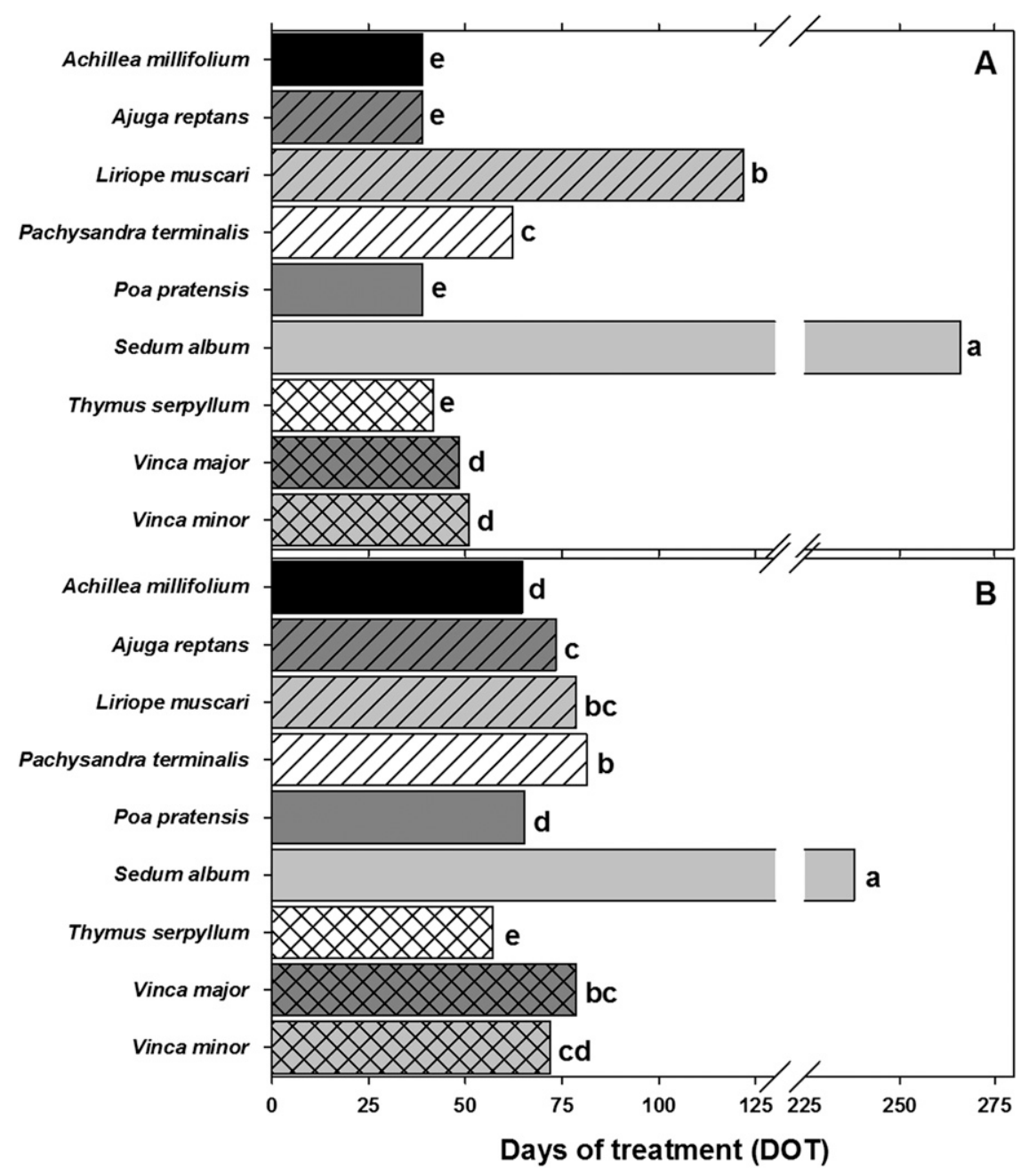

Fig. 2. Number of days to decline to a drought rating of one among species during the spring/summer [(A) (began 18 May 2010)] and fall [(B) (began 27 Sept. 2010)]; termination dates of each study varied with species (see text for details). Means followed by the same letter within each study period are not significantly different $(P=0.05)$.

Table 1 . Average percentage of pot cover after $60 \mathrm{~d}$ of recovery from each drydown.

\begin{tabular}{|c|c|c|}
\hline Species & $\begin{array}{l}\text { Spring/summer } 2010 \\
\text { Recovery after } 60 \mathrm{~d}\end{array}$ & $\begin{array}{c}\text { Fall } 2010 \\
\text { Recovery after } 60 \mathrm{~d}\end{array}$ \\
\hline Achillea millifolium & $\mathrm{NR}^{\mathrm{Z}}$ & $\mathrm{NR}$ \\
\hline Ajuga reptans & NR & NR \\
\hline Liriope muscari & NR & NR \\
\hline Pachysandra terminalis & NR & NR \\
\hline Poa pratensis & $46 \% \mathrm{PC}^{\mathrm{y}}$ & NR \\
\hline Sedum album & $38 \% \mathrm{PC}$ & NR \\
\hline Thymus serpyllum & NR & NR \\
\hline Vinca major & $35 \% \mathrm{PC}$ & NR \\
\hline Vinca minor & NR & NR \\
\hline
\end{tabular}

${ }^{\mathrm{z}} \mathrm{NR}=$ no recovery. The plants did not recover within $60 \mathrm{~d}$; therefore, no data were collected.

${ }^{\mathrm{y}} \mathrm{PC}=$ pot cover. The area of the container that was covered with vegetation after $60 \mathrm{~d}$. 
also remained higher than 6 through Week 6 of the spring/summer study. $V$. minor and $V$. major maintained higher drought ratings longer than the remainder of the species in both studies with the exception of $P$. terminalis, which varied more between the spring/summer and fall studies than the other species. Thus, $S$. album, L. muscari, V. major, V. minor, and $P$. terminalis may be able to maintain quality longer than other species evaluated in landscapes experiencing extended periods of drought. The drought ratings of $A$. millifolium, $A$. reptans, $P$. pratensis, and $T$. serpyllum dropped below 3 by Week 6 in both studies (Fig. 1), indicating that they may have less ability to maintain their quality during severe drought than the remainder of species.

When evaluating the overall period of decline in quality to a drought rating of 1 among species, S. album persisted two to three times longer than the next best performing species during drought; $S$. album required $266 \mathrm{~d}$ in the spring/summer and $241 \mathrm{~d}$ in the fall before declining to a drought rating of 1 (Fig. 2). The drought ratings of L. muscari and $P$. terminalis also declined slower than the remainder of species in the spring/summer, taking $122 \mathrm{~d}$ and $62 \mathrm{~d}$, respectively, to decline to a drought rating of 1 . In the fall, L. muscari and $P$. terminalis also persisted well although their superiority was not as pronounced as in the spring/summer.

In the spring/summer, the fastest decline to a drought rating of 1 among species was in $A$. reptans, $A$. millifolium, and $P$. pratensis (39 d each) and in T. serpyllum (42 d) (Fig. 2). This is similar to the initial trend observed among these four species during the first 6 weeks in both studies (Fig. 1). In the fall, $T$. serpyllum declined the fastest followed by A. millifolium, $P$. pratensis, and $V$. minor. Thus, in both studies, the persistence in higher drought rating was generally least in T. serpyllum, A. millifolium, and $P$. pratensis. Although the drought rating of $A$. reptans remained above 1 longer than the latter three species in the fall, its low drought rating by Week 6 (Fig. 1) combined with its rapid decline in the spring/summer (Fig. 2) indicates a generally low endurance to prolonged drought.

Only three species recovered from the drought during the spring/summer: $P$. pratensis, $S$. album, and $V$. major (Table 1). Given the general lack of recovery among species, it is likely that most had surpassed the permanent wilting point by the time they received a drought rating of 1 . The recovery in $P$. pratensis, which was the highest among species at the end of the 60-d recovery period, indicates its capacity to recover well from complete dormancy. Richardson et al. (2009) reported similar results in the recovery of 14 cultivars of $P$. pratensis after a severe drydown, in which irrigation was withheld until plots reached $25 \%$ green cover. Those authors found that all cultivars recovered to $50 \%$ green cover after 4.2 to 18.9 d of recovery. Also, Merewitz et al. (2010) evaluated four $P$. pratensis cultivars through a 5-week drought and the recovery after resuming irrigation. They reported almost full recovery of all four cultivars after 30 d. Goldsby (2013) reported complete recovery in $P$. pratensis after 60 to $88 \mathrm{~d}$ without irrigation, although after $88 \mathrm{~d}$ in the first year of a 2-year study, full recovery was not observed until the next spring. Bousselot et al. (2011) reported that droughtstressed $S$. album recovered to 58\% pot cover, which was higher than in the present study; the length of the recovery period was not reported in their study.

In the present study, none of the species recovered from prolonged drought in the fall (Table 1), probably because of a $51 \%$ increase in vapor pressure deficit (VPD) that was caused, in part, by the presence of artificial lights and the evaporative greenhouse cooling system not operating for the season; daytime (0600 to 2000 HR Central Standard Time) VPD inside the greenhouse averaged much lower in the spring/summer $(1.04 \mathrm{kPa})$ than the fall
$(2.13 \mathrm{kPa})$. For reasons unknown, the leaves retained green pigment longer than in the spring/summer, even after the leaves were completely desiccated. The delayed loss of green pigment in the fall probably delayed the time when most species received a rating of 1 compared with the spring/summer study. This probably confounded the results and contributed to the interactions observed between the spring/summer and fall studies.

Volumetric soil water content. The decline in $\theta_{\mathrm{v}}$ was more rapid in the fall than in the spring/summer, illustrating the effects of higher VPD on evapotranspiration rates in the fall (Figs. 3 and 4). By Week 6 in the spring/summer, $\theta_{\mathrm{v}}$ in pots containing $S$. album, $P$. terminalis, and $L$. muscari remained higher than $12 \%$, which was just above the permanent wilting point; soil moisture release curves for this soil indicated the permanent wilting
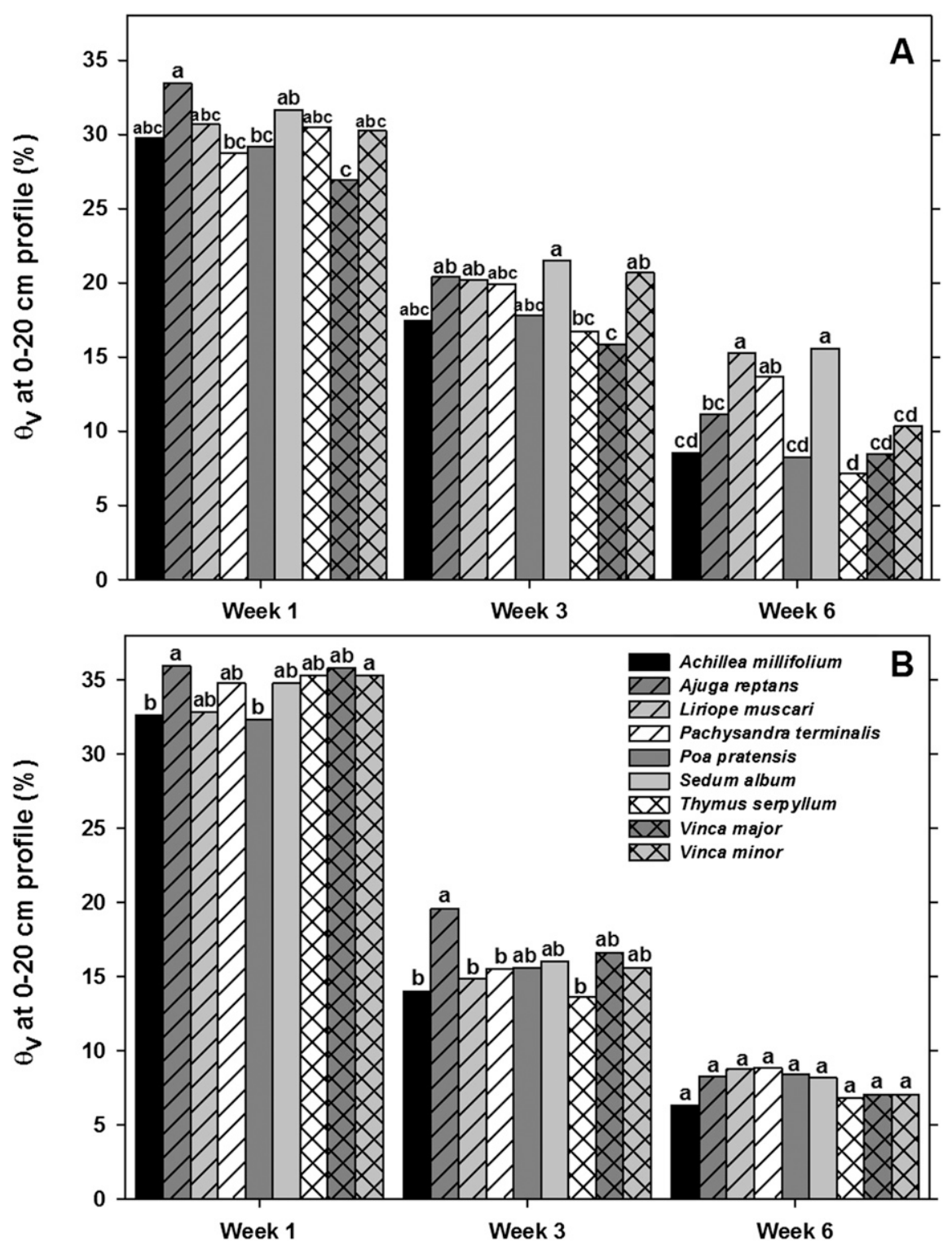

Fig. 3. Volumetric soil water content $\left(\theta_{\mathrm{v}}\right)$ of each species for Weeks 1,3 , and 6 of the spring/summer [(A) (began 18 May 2010)] and the fall [(B) (began 27 Sept. 2010)] drydown. Termination dates of each study varied with species (see text for details). Means followed by the same letter within each week are not significantly different $(P=0.05)$. 


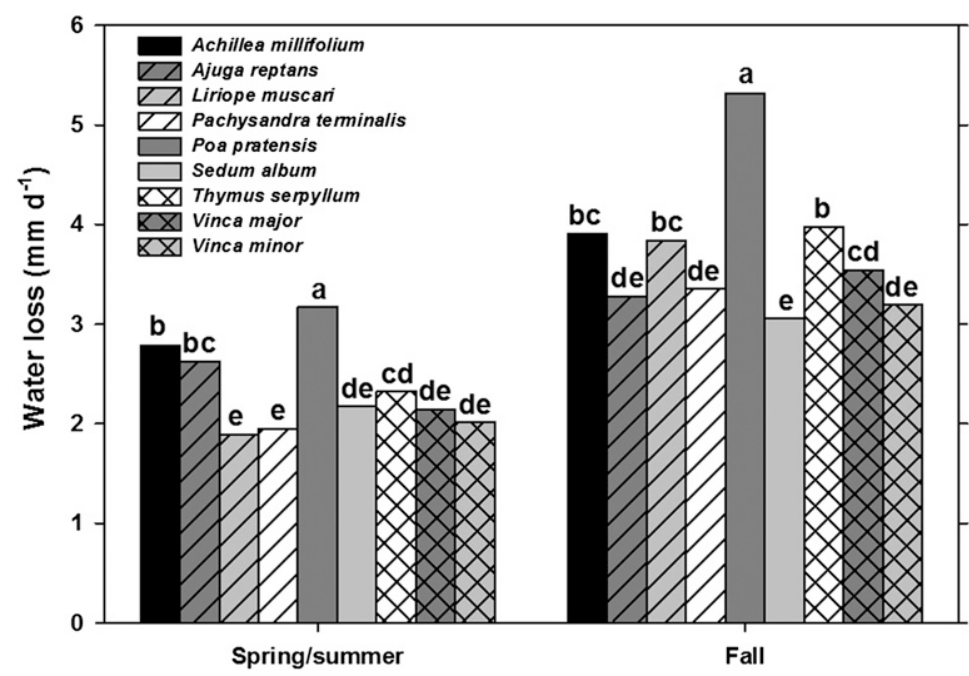

Fig. 4. Average water loss $\left(\mathrm{mm} \cdot \mathrm{d}^{-1}\right)$ of each species for the first $3 \mathrm{~d}$ of the spring/summer (began $18 \mathrm{May}$ 2010) and the fall (began 27 Sept. 2010) drydowns. Termination dates of each study varied with species (see text for details). Means followed by the same letter within each drydown (spring/summer and fall) are not significantly different $(P=0.05)$.

point (soil water potential $=-1.5 \mathrm{MPa}$ ) was equivalent to $\theta_{\mathrm{v}}=11.1 \%$ (data not shown). This $\left(\theta_{\mathrm{v}}\right.$ greater than $\left.12 \%\right)$ was significantly higher than the other species with the exception of $P$. terminalis, which was similar to A. reptans (Fig. 3A). This, along with the number of days for $S$. album, $P$. terminalis, and L. muscari $(266 \mathrm{~d}, 62 \mathrm{~d}$, and $122 \mathrm{~d}$, respectively) to decline to a drought rating of 1 in the spring/summer (Fig. 2A), indicates these species were using less water than the other species. In the fall, $\theta_{\mathrm{v}}$ was similar among species and all were below $10 \%$ by Week 6 , indicating soil water potential was below $-1.5 \mathrm{MPa}$ and had reached permanent wilting point (Fig. 3B). Bousselot et al. (2011) reported the average number of days for $\theta_{\mathrm{v}}$ to drop below $10 \%$ was just over $6 \mathrm{~d}$ for four Sedum species being evaluated for use on a green roof. However, the Sedum species in their study were being grown in smaller nursery pots $(15.2 \mathrm{~cm}$ diameter $\times 10.8 \mathrm{~cm}$ deep) with a lightweight potting mix as a substrate.

Water loss rates from well-watered containers. Because landscape plants are often maintained under well-watered conditions, this study afforded an opportunity to compare relative rates of water use [evapotranspiration (ET)] among species. We assumed that all species were well watered during the first $3 \mathrm{~d}$ of the drydown, when soils were at or near field capacity. It is important to note that as the study progressed and the soils dried, leaves desiccated and dropped, and the water status and physiology changed in the plants; the relationships in ET among species also probably changed. Thus, the ET rates under wellwatered conditions may not be reflected in the long-term volumetric water content presented in the previous section.

Because the nursery containers were not sealed on the bottom, the observed water losses from the containers could not be attributed entirely to ET. Although free drainage had ceased before the containers were first weighed, it is likely that some water evaporated through the holes in the bottom of the containers (Bremer, 2003). However, because all containers were the same, it is likely that evaporation through the holes, although small, was similar among containers. Thus, the differences in water loss among species are likely caused by differences in ET. In the first $3 \mathrm{~d}$, water loss likely represented relative differences in ET among species under wellwatered conditions (Fig. 4).

During the first $3 \mathrm{~d}$ of the spring/summer study, water loss was highest among species in P. pratensis at $3.17 \mathrm{~mm} \cdot \mathrm{d}^{-1}$ (Fig. 4), although evapotranspiration in the greenhouse does not always equate to ET in the field, especially under windy conditions. During the same period, water loss rates of A. millifolium and $A$. reptans were also high at $2.78 \mathrm{~mm} \cdot \mathrm{d}^{-1}$ and $2.62 \mathrm{~mm} \cdot \mathrm{d}^{-1}$, respectively, although the rate of water loss in T. serpyllum was similar to A. reptans. By Week 3, water loss continued to be the highest among species in A. millifolium, $A$. reptans, $P$. pratensis, and $T$. serpyllum (data not shown). Higher water loss in these four species early in the spring/summer likely contributed to their faster decline in visual quality among species as soils dried (Figs. 1 to 3 ).

In the spring/summer study, water loss rates in the remaining five species were similarly low during the first $3 \mathrm{~d}$ under wellwatered conditions (Fig. 4). By Week 3, however, S. album and L. muscari had the lowest water loss rates among species (data not shown). Interestingly, high visual quality in the latter two species also persisted longer among species in the spring/summer.

In the fall study, under well-watered conditions, water loss rates among species averaged $37 \%$ higher than in the spring/summer (Fig. 4), primarily because of higher VPD in the fall. The highest water loss rate during the first $3 \mathrm{~d}$ of the fall was in $P$. pratensis at $5.32 \mathrm{~mm} \cdot \mathrm{d}^{-1}$. After $P$. pratensis, the highest water loss rates were in T. serpyllum (3.97 $\left.\mathrm{mm} \cdot \mathrm{d}^{-1}\right)$, A. millifolium $\left(3.91 \mathrm{~mm} \cdot \mathrm{d}^{-1}\right)$, and
L. muscari $\left(3.84 \mathrm{~mm} \cdot \mathrm{d}^{-1}\right)$. Higher water use rates in these species probably contributed to their faster decline in quality among species with the notable exception of $L$. muscari, which maintained acceptable quality even by Week 6 (Figs. 1B and 2B). It is possible that $L$. muscari may have retained sufficient pigments during the rapid drydown in the fall to receive inflated drought ratings even after the plants had died.

Stomatal conductance. Stomatal conductance was highest among species early in both studies and generally began to decline around Day 10 in the spring/summer and Day 5 in the fall as the soil dried (Fig. 5). Declines in $g_{\mathrm{S}}$ may have helped the plants maintain leaf water status by slowing the rate of water loss from the leaves (Hopkins, 1999; Kirkham, 2005; Taiz and Zeiger, 2006). In the spring/ summer, the increase in $g_{\mathrm{S}}$ on the second measurement day DOT 7) was associated with an increase in $P A R$ from 472 to 697 $\mu \mathrm{mol} \cdot \mathrm{m}^{-2} \cdot \mathrm{s}^{-1}$.

In the spring/summer, $g_{\mathrm{S}}$ in $P$. pratensis was high early in the study but declined sooner than the other species with the exception of $L$. muscari, which was consistently low (Fig. 5A), and $A$. reptans. By Day $17, g_{\mathrm{S}}$ in $P$. pratensis had decreased to less than $V$. major, $V$. minor, and $P$. terminalis. Stomatal conductance in $A$. reptans was also lower than $V$. major and $V$. minor on Day 23. The faster decline in $g_{\mathrm{S}}$ in $P$. pratensis and, to a lesser degree, $A$. reptans may have resulted from their higher water use among species early in the study, which would presumably deplete soil moisture faster (Fig. 4).

Although measurements of $g_{\mathrm{S}}$ are useful indicators of water relations in plants, differences in leaf area index among species may have confounded our measurements of $g_{\mathrm{S}}$ as they relate to total water use. For example, overall ET may be less from a species with high $g_{\mathrm{S}}$ but low leaf area index than in another species with lower $g_{\mathrm{S}}$ and greater leaf area index. Unfortunately, we were not able to measure green leaf area index because plants had either died or were dormant by the end of the drydowns.

In L. muscari, $g_{\mathrm{S}}$ was never higher than $100 \mathrm{mmol} \cdot \mathrm{m}^{-2} \cdot \mathrm{s}^{-1}$ in the spring/summer and $130 \mathrm{mmol} \cdot \mathrm{m}^{-2} \cdot \mathrm{s}^{-1}$ in the fall (Fig. 5). In $P$. terminalis, $g_{\mathrm{S}}$ was also consistently low in the fall with measurements never higher than $170 \mathrm{mmol} \cdot \mathrm{m}^{-2} \cdot \mathrm{s}^{-1}$. Interestingly, $g_{\mathrm{S}}$ in $P$. terminalis started moderately low in the spring/ summer study but then increased slightly on Days 7 and 11 to Day 17, after which it declined rapidly. Lower $g_{\mathrm{S}}$ of $L$. muscari and $P$. terminalis undoubtedly contributed to their low ET among species (Fig. 4).

No significant differences were found in $g_{\mathrm{S}}$ among the species after 31 DOT in the spring/summer and 26 DOT in the fall (Fig. 5). All $g_{\mathrm{S}}$ measurements were below detectable limits by 35 DOT in both studies, indicating complete stomatal closure. Other studies evaluating drought stress of plants grown in a greenhouse reported similar results. Ranney et al. (1991) reported $g_{S}$ of six birch (Betula) trees was no longer detectable around Day 


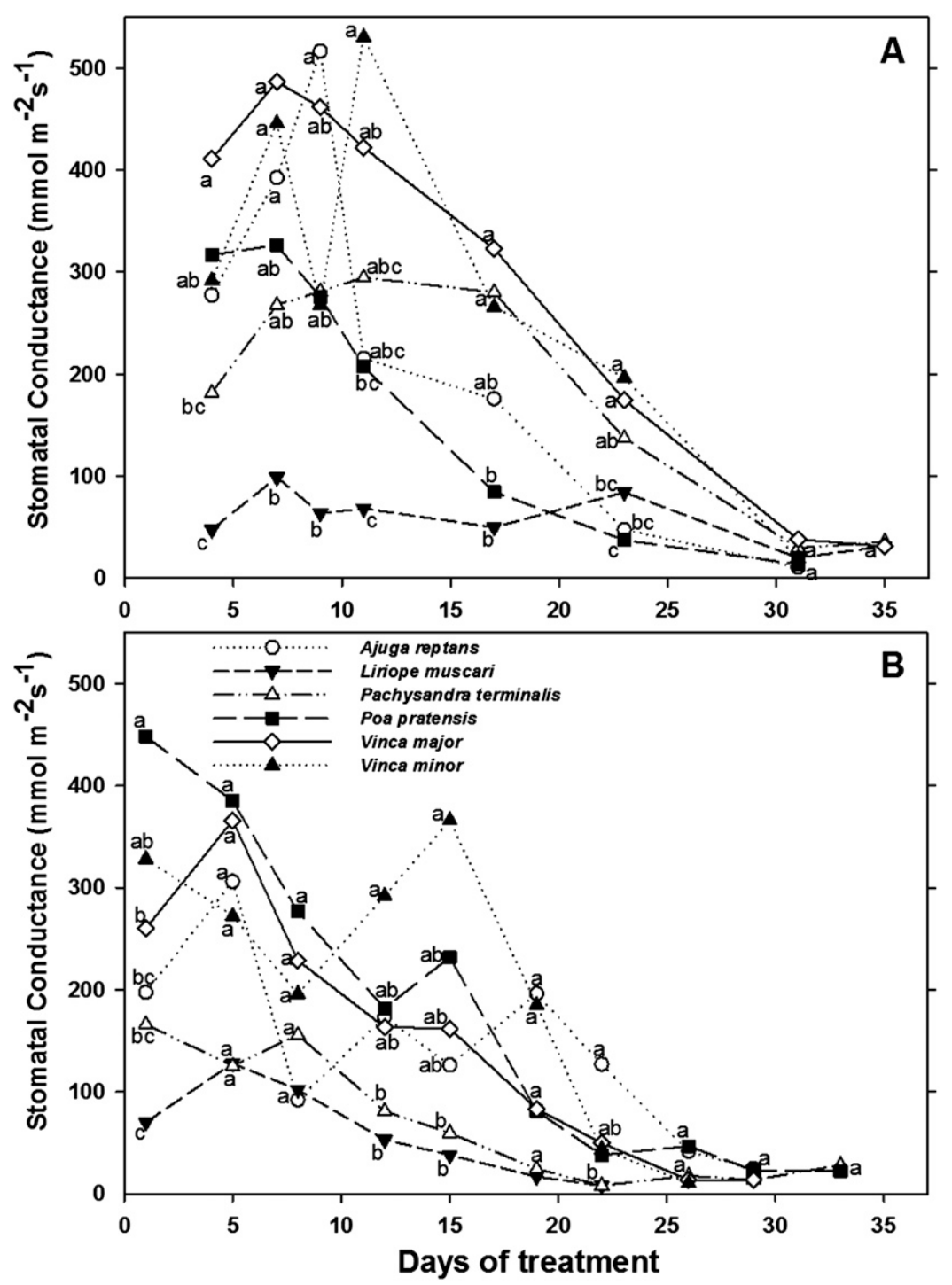

Fig. 5. Stomatal conductance $\left(g_{\mathrm{S}}\right)$ among species as the soils dried during the spring/summer [(A) (began 18 May 2010)] and the fall [(B) (began 27 Sept. 2010] drydown. Termination dates of each study varied with species (see text for details). Means followed by the same letter within each measurement day are not significantly different $(P=0.05)$.

32 of a drydown; and Huang and Gao (1999) were not able to detect $g_{\mathrm{S}}$ of Festuca spp. after $28 \mathrm{~d}$ of drought.

\section{Conclusions}

Results indicate S. album, L. muscari, and $P$. terminalis may be more successful in landscapes where severe drought may occur than the other species evaluated because of their ability to maintain higher drought ratings and $\theta_{\mathrm{v}}$ for longer periods during drought. $V$. major and $V$. minor may also be good selections in landscapes with intermittent or less severe droughts. P. pratensis may also be a good selection if periods of reduced quality or dormancy are acceptable to homeowners. Although the quality of $P$. pratensis declined relatively quickly among species, our results as well as research by others has demonstrated $P$. pratensis has a remarkable ability to recover from severe drought-induced dormancy (Goldsby, 2013). A. millifolium, A. reptans, and T. serpyllum appeared least adaptable to severe drought.

Because this study was conducted in a greenhouse, further research is needed to investigate the drought stress and water status of A. millifolium, A. reptans, L. miscari, $P$. pratensis, P. terminals, S. album, T. serpyllum, $V$. major, and $V$. minor under field conditions.

\section{Literature Cited}

Alig, R.J., J.D. Kline, and M. Lichtenstein. 2004. Urbanization on the US landscape: Looking ahead in the 21st century. Landsc. Urban Plan. 69:219-234.

Bousselot, J.M., J.E. Klett, and R.D. Koski. 2010 Extensive green roof species evaluations using digital image analysis. HortScience 45:12881292.

Bousselot, J.M., J.E. Klett, and R.D. Koski. 2011. Moisture content of extensive green roof substrate and growth response of 15 temperate plant species during dry down. HortScience 46:518-522.

Bremer, D.J. 2003. Evaluation of microlysimeters used in turfgrass evapotranspiration studies using the dual-probe heat-pulse technique. Agron. J. 95:1625-1632.

Christians, N. 2004. Fundamentals of turfgrass management. $2^{\text {nd }}$ Ed. John Wiley and Sons, Inc., Hoboken, NJ.

Devitt, D.A. and R.L. Morris. 2008. Urban Landscape water conservation and the species effect, p. 171-192. In: Beard, J.B. and M.P. Kenna (eds.). Water quality issues for turfgrasses in urban landscapes. Council for Agricultural Sciences and Technology, Ames, IA.

Domenghini, J., D.J. Bremer, J.D. Fry, and G.L. Davis. 2013. Evapotranspiration and performance among turfgrass and ornamental landscape species in response to irrigation deficit. Intl. Turf. Soc. Res. J. 405-414.

Fu, J., J. Fry, and B. Huang. 2004. Minimum water requirements of four turfgrasses in the transition zone. HortScience 39:1740-1744.

Goldsby, A. 2013. Establishment, drought tolerance and recovery, and canopy analysis of turfgrasses in the transition zone. $\mathrm{PhD}$ diss., Kansas State Univ., Manhattan, KS.

Hook, J.E., W.W. Hanna, and B.W. Maw. 1992. Quality and growth response of Centipedegrass to extended drought. Agron. J. 84:606-612.

Hopkins, W.G. 1999. Introduction to plant physiology. 2nd Ed. John Wiley and Sons, Inc., New York, NY.

Huang, B. and H. Gao. 1999. Physiological responses of diverse tall fescue cultivars to drought stress. HortScience 34:897-901.

Jiang, Y. and B. Huang. 2001. Physiological responses to heat stress alone or in combination with drought: A comparison between tall fescue and perennial ryegrass. HortScience 36:682686.

Karcher, D.E., M.D. Richardson, K. Hignight, and D. Rush. 2008. Drought tolerance of tall fescue populations selected for high root/shoot ratios and summer survival. Crop Sci. 48:771-777.

Keeley, S.J. and A.J. Koski. 2001. Dehydration avoidance of diverse Poa pratensis cultivars and cultivar groups in a semi-arid climate. Intl. Turfgrass Soc. Res. J. 9:311-316.

Kircher, W. 2004. Annuals and Sedum-cuttings in seed-mixtures for extensive roof gardens. Acta Hort. 643:301-303.

Kirkham, M.B. 2005. Principles of soil and plant water relations. Elsevier Academic Press, Burlington, MA.

Liu, J., X. Kie, J. Du, J. Sun, and X. Bai. 2007. Effects of simultaneous drought and heat stress on kentucky bluegrass. Sci. Hort. 115:190195 .

Lyman, G.T., C.S. Throssell, M.E. Johnson, G.A. Stacey, and C.D. Brown. 2007. Golf course profile describes turfgrass, landscape and environmental stewardship features. Online. Applied Turfgrass Science. doi:10.1094/ATS-2007-110707-RS.

Merewitz, E., W. Meyer, S. Bonos, and B. Huang. 2010. Drought stress responses and recovery of Texas $\times$ kentucky hybrids and kentucky bluegrass genotypes in temperate climate conditions. Agron. J. 102:258-268.

Monterusso, M.A., D.B. Rowe, and C.L. Rugh 2005. Establishment and persistence of Sedum spp. and native taxa for green roof applications. HortScience 40:391-396.

Morris, K.N. 2000. Guidelines for using NTEP trial data. Golf Course Mgt. 68:64-69.

Phillips, E. and C.C. Burrell. 1993. Illustrated encyclopedia of perennials. Rodale Press Inc., Emmaus, PA.

Qian, Y. and J.D. Fry. 1997. Water relations and drought tolerance of four turfgrasses. J. Amer. Soc. Hort. Sci. 122:129-133. 
Ranney, T.G., R.E. Bir, and W.A. Skroch. 1991. Comparative drought resistance among six species of birch (Betula): Influence of wild water stress on water relations and leaf gas exchange. Tree Physiol. 8:351-360.

Richardson, M.D., D.E. Karcher, K. Hignight, and D. Rush. 2008. Drought tolerance and rooting capacity of kentucky bluegrass cultivars. Crop Sci. 48:2429-2436.

Richardson, M.D., D.E. Karcher, K. Hignight, and D. Rush. 2009. Drought tolerance of kentucky bluegrass and hybrid bluegrass cultivars. Online.
Applied Turfgrass Science. doi:10.1094/ATS2009-0112-01-RS.

Sayed, O.H., M.J. Earnshaw, and M. Cooper. 1994. Growth, water relations, and CAM induction in Sedum album in response to water stress. Biol. Plant. 36:383-388.

Smith, J. and T. Brown. 2003. Water efficient irrigation study final report. $<$ http://www.irrigation org/swat/images/puget_sound.pdf $>$.

Staats, D. and J.E. Klett. 1995. Water conservation potential and quality of non-turf groundcovers versus kentucky bluegrass under increasing levels of drought stress. Journal of Environmental Horticulture 14:181-185.

Steinke, K., D. Chalmers, J. Thomas, R. White, and G. Fipps. 2010. Drought response and recovery characteristics of St. Augustinegrass cultivars. Crop Sci. 50:2076-2083.

Taiz, L. and E. Zeiger. 2006. Plant physiology. 4th Ed. Sinauer Associates, Inc., Sunderland, MA. Turgeon, A.J. 2005. Turfgrass management. 7th Ed. Pearson Education, Inc., Upper Saddle River, NJ. WaterSense. 2008. U.S. EPA. 4 Feb. 2013. <http:// www.epa.gov/WaterSense/>. 